\title{
Measuring and modelling the soil shrinkage characteristic curve
}

\author{
W.M. Cornelis ${ }^{\text {a,* }}$, J. Corluy ${ }^{\text {b }}$, H. Medina ${ }^{\text {c }}$, J. Díaz $^{c}$, R. Hartmann ${ }^{\text {a }}$, \\ M. Van Meirvenne ${ }^{\mathrm{a}}$, M.E. Ruiz ${ }^{\mathrm{c}}$ \\ ${ }^{a}$ Department of Soil Management and Soil Care, Ghent University, Coupure links 653, 9000 Gent, Belgium \\ ${ }^{\mathrm{b}}$ Department of Hydrology and Hydraulic Engineering, Free University Brussels, Pleinlaan 2, 1050 Brussels, Belgium \\ ${ }^{c}$ Grupo de Investigaciones Agrofisicas, Universidad Agraria de la Habana, Apdo 18 San José de las Lajas, Habana 32700, Cuba
}

Received 6 September 2005; received in revised form 28 June 2006; accepted 15 August 2006

Available online 5 October 2006

\begin{abstract}
The macroporosity, and to a lesser extent the microporosity, of swelling and shrinking soils is affected by their shrinkage behaviour. The magnitude of the changes in bulk volume in response to changes in water content is usually described by the soil shrinkage characteristic curve (SSCC), i.e. the relation between the void ratio and the moisture ratio. At present, many techniques have been described for determination of the SSCC. We have applied the core method, the rubber-balloon method and the paraffin-coated method on respectively undisturbed soil samples, disturbed soil samples and soil clods collected from seven horizons of a Vertisol and a Lixisol under sugar cane in the Havana province, Cuba. We demonstrated that the balloon and paraffin-coated method showed similar results, whereas the core method produced less pronounced shrinkage. The latter was due to the anisotropic shrinkage as was confirmed by the change of the geometry factor with the moisture ratio, to a possible reorientation of particles when collecting undisturbed soil cores, and to the occurrence of small cracks upon drying. We have further shown that the core method produced much higher scatter, which was explained by higher measuring errors and crumbling of the samples as they dried out. Because of its superior behaviour, the balloon method was then selected to test nine different parametric models that describe the SSCC. A group of four models which performed best in terms of RMSE, coefficient of determination and Akaike Information Criterion could be distinguished. These models include the three linear equations model of McGarry and Malafant [McGarry, D., Malafant, K.W.J., 1987. The analysis of volume change in unconfined units of soil. Soil Sci. Soc. Am. J. 51, 290-297], the combined linear and exponential five equations model of Braudeau et al. [Braudeau, E., Costantini, J.M., Bellier, G., Colleuille, H., 1999. New device and method for soil shrinkage curve measurement and characterization. Soil Sci. Soc. Am. J. 63, 525-535], a modified version of the theoretical three equations model of Chertkov [Chertkov, V.Y., 2000. Modeling the pore structure and shrinkage curve of soil clay matrix. Geoderma 95, 215-246] and a simplified version of the logistic model of Groenevelt and Grant [Groenevelt, P.H., Grant, C.D., 2001. Re-evaluation of the structural properties of some British swelling soils. Eur. J. Soil Sci. 52, 469-477]. Though performing very well, the McGarry and Malafant model does not describe the complete SSCC, whereas the Braudeau et al. model contains a relatively large number of parameters. Overall highest performance was observed for the modified Chertkov model. The modified Groenevelt and Grant model, however, has the advantage of being the most elegant as it consists of only one single equation. (C) 2006 Elsevier B.V. All rights reserved.
\end{abstract}

\section{Introduction}

Swelling and shrinking clay soils change in volume with water content changes. These volume changes depend on the amount and type of clay minerals and are characterized by their magnitude and geometry. They result in the occurrence of shrinkage cracks and surface subsidence. Assessing the magnitude and geometry of cracks is important for modelling infiltration at the soil surface and subsequent redistribution of

\footnotetext{
* Corresponding author. Tel.: +32926460 40; fax: +3292646247.

E-mail address: wim.cornelis@UGent.be (W.M. Cornelis).
}

water within the soil. Both processes are different compared to non-shrinking soil due to surface runoff and preferential flow in the cracks. The latter process is known as bypass flow or short circuiting (Hoogmoed and Bouma, 1980). Modelling of water transport in the vadose zone of the soil hence not only requires the soil-water characteristic curve and hydraulic conductivity, but also a third relationship, being the soil shrinkage characteristic curve (SSCC), which relates a water content related variable to a pore volume related variable.

Generally, when a swelling and shrinking clay soil dries out, four shrinkage stages can be distinguished (Haines, 1923; Stirk, 1954; Bronswijk, 1991): (1) structural shrinkage, (2) normal 
shrinkage, (3) residual shrinkage and (4) zero shrinkage (see Fig. 1). In the first stage, the large inter-aggregate pores and the biological tubular pores - worm and root channels - are emptied without considerable change in bulk volume, and air enters these relatively large pores. This stage only occurs in structured well-aggregated soils or soils with considerable biological activity. In the second stage, the decrease in water volume results in an equal decrease in bulk soil volume, with the intra-aggregate pores still being fully saturated. In the case of a structureless clay paste, the slope is equal to 1 (Sposito and Giráldez, 1976; Chertkov, 2000, 2003), whereas in structured soils, the slope can be much smaller than 1 and as low as 0.1 (Braudeau et al., 1999). Mitchell (1992) therefore suggested calling this stage basic shrinkage rather than normal shrinkage, whereas Groenevelt and Grant (2001) used the term proportional. In the third stage, air enters the intra-aggregate pores and a further decrease in water upon drying hence exceeds the volume change of the aggregates (and the bulk soil). Finally, in the fourth stage, the soil particles have reached their densest configuration and the volume of the aggregates remains unaltered as the water volume further decreases (Bronswijk, 1991). Bruand and Prost (1987) demonstrated, however, that during this fourth phase, reorganisation of clay particles does occur, leading to the formation of microscopic cracks. Since both phenomena have a compensating effect, the aggregate volume remains unaltered (Bruand and Prost, 1987). They further observed during stages 2 and 3, shrinkage of the millimetric domains which build up the soil aggregates. This shrinkage results in millimetric cracks which enclose those millimetric domains. As the number of millimetric domains increases with aggregate size, larger aggregates show a higher volume of voids relative to the volume of solids (Bruand and Prost, 1987) and the shrinkage behaviour of the sample becomes less pronounced.

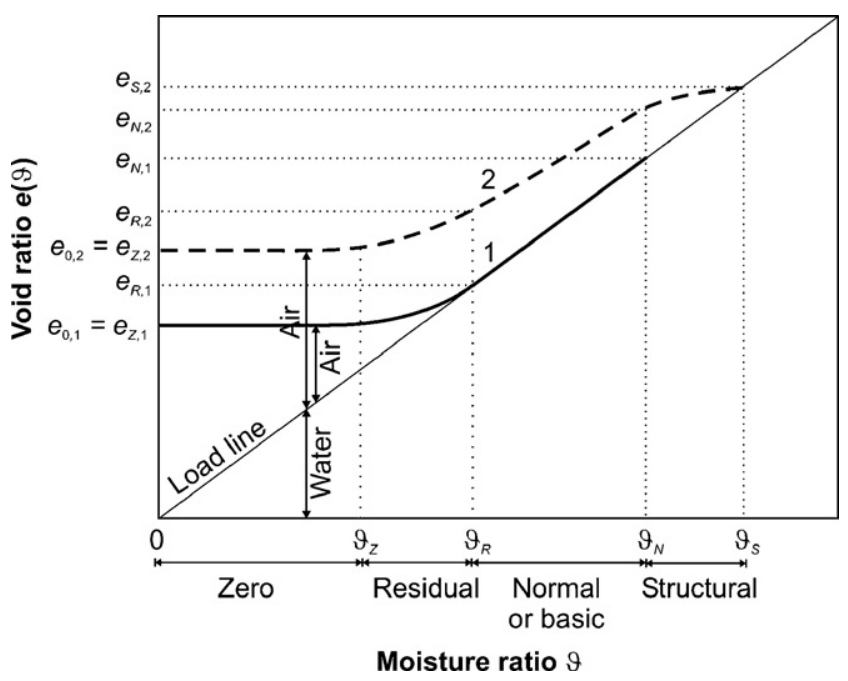

Fig. 1. Schematic presentation of a soil shrinkage characteristic curve of a nonstructured soil (solid line, 1) and a well-structured soil (dashed line, 2). The subscripts associated with the moisture ratio $\vartheta$ and the void ratio $e$ denote for $\mathrm{S}$, $\mathrm{N}, \mathrm{R}$, and Z, respectively (1) structural, (2) normal or basic, (3) residual and (4) zero shrinkage, whereas the subscripts 1 and 2 refer to respectively a nonstructured soil and a well-structured or biological active soil.
Determination of the SSCC requires simultaneous measurement of the pore volume and the volume of water in a known volume of soil over the whole range of water contents, from saturation till oven dryness. Numerous techniques for determining the SSCC have been proposed. Many authors suggested determining the bulk volume of soil by measuring the weight or volume of a fluid displaced by variably saturated soil samples using Archimedes' principle. Soil samples were submerged in fluids such as kerosene or petroleum (McIntyre and Stirk, 1954; Monnier et al., 1973), toluene (Sibley and Williams, 1989) and mercury (ASTM, 2005), or were first coated with paraffin (Lauritzen and Stewart, 1941; Johnston and Hill, 1944; Lauritzen, 1948) or saran resin dissolved in methyl ethyl ketone (Brasher et al., 1966). Pellissier (1991) used a combination method in which toluene was used as the submergible fluid for the wet part of the SSCC, and water for the dry end when air enters into the soil. Before submerging the clods in water, they were dipped in molten wax, and at further drying, the wax was removed and the clod was sprayed with a freezing liquid.

Another approach for measuring the bulk soil volume is by measuring the dimensions of the soil sample directly. Berndt and Coughlan (1976) recorded the height and diameter of undisturbed soil cores as they dried out. A similar procedure was followed by Yule and Ritchie (1980a,b). Schafer and Singer (1976) filled columns with disturbed soil and followed the decrease in length of the drying rod-shaped soil column. Braudeau (1987) measured the reduction in sample dimensions upon drying by using a retractometer, which was later modified by Braudeau and Boivin (1995) and Braudeau et al. (1999). It allows continuous monitoring of the diameter of a cylindrical soil sample in the vertical direction using several laser sensors.

Michel et al. (2000) adapted a triaxial apparatus to allow the tracing of the isotropic character of shrinking soil. The limitations associated with many of these methods lead Tariq and Durnford (1993a) to design an alternative and very simple method to determine the SSCC. Disturbed or undisturbed soil samples were saturated and surrounded by an ordinary rubber balloon. The sample was dried by air flowing at low pressure over the sample. At given times, the soil sample and the balloon were submerged in water and the bulk soil volume was then determined by the volume of water which it displaced. All the above methods allow soil water to be related to pore volume.

To model water and solute transport in the soil, a continuous SSCC is required, rather than a set of discrete experimental data pairs that can be obtained experimentally using the approaches listed previously. Several models that can be fitted to a set of discrete data pairs are reported in literature and include polynomial models (Giráldez et al., 1983; Giráldez and Sposito, 1983), linear models consisting of different straight lines for the different shrinkage phases (McGarry and Malafant, 1987), logistic models (McGarry and Malafant, 1987), and sigmoid models (Groenevelt and Grant, 2001, 2002; Cornelis et al., 2006). Kim et al. (1992), Tariq and Durnford (1993b) and Braudeau et al. (1999) suggested combining exponential or polynomial function with linear ones. These models all require greater verification using data sets independent from those applied in previous studies. Since those models have been 
previously tested using different methods, their evaluation using one single method is highly recommended.

Besides the magnitude of volume changes upon wetting and drying, which is described by the SSCC, the geometry of swelling and shrinking is of equally importance for modelling water transport in a swelling and shrinking soil. When representing a given soil volume by an isolated cube (Bronswijk, 1990; Chertkov et al., 2004; Chertkov, 2005), changes in volume can be described as:

$1-\frac{\Delta V}{V}=\left(1-\frac{\Delta z}{z}\right)^{r_{\mathrm{s}}}$

where $V$ is the original soil bulk volume, $\Delta V$ is the volume change upon shrinkage, $z$ is the original height, $\Delta z$ is the surface subsidence, and $r_{\mathrm{s}}$ is the geometry factor first defined by Rijniersce (1983) in a study on pedogenitically unripe soils. For three dimensional isotropic shrinkage, $r_{\mathrm{s}}$ is equal to 3 . When cracking dominates subsidence, $r_{\mathrm{s}}>3$, and in the case of subsidence only, $r_{\mathrm{s}}$ is 1 . Modelling of changes in soil bulk volume, crack area and surface subsidence as a function of the void ratio was demonstrated in Cornelis et al. (2006).

The objectives of this paper were

(1) to compare three methods to determine the volume change of the soil matrix, i.e. a soil volume without cracks, upon shrinkage. These methods were the core method of Berndt and Coughlan (1976) on undisturbed soil cores, the balloon method of Tariq and Durnford (1993a) in which disturbed soil samples were applied, and the paraffincoated method of Lauritzen and Stewart (1941) for individual soil clods;

(2) to test the performance of the models of Giráldez et al. (1983), McGarry and Malafant (1987), Kim et al. (1992), Tariq and Durnford (1993b), Olsen and Haugen (1998), Braudeau et al. (1999), a modified version of the Chertkov model $(2000,2003)$, and the simplified notation of the Groenevelt and Grant $(2001,2002)$ model as suggested by Cornelis et al. (2006).

The above methods and models were tested on soil samples collected on a Vertisol and a Lixisol which were under sugar cane in the Havana province, Cuba. Before describing these soils and the followed methodology, the selected models will be first described in more detail.

\section{Some considerations about the selected SSCC methods}

In comparing the methods to determine the SSCC, the paraffin-coated method of Lauritzen and Stewart (1941) is considered in our study as a reference. This method was selected because clods can be obtained by breaking soil after it has been subjected to shrinkage. As such, the method represents the shrinkage behaviour of the soil matrix, rather than the bulk soil with cracks, relatively well. This allows modelling changes in crack area and surface subsidence (outside the soil matrix) by assessing changes of the soil matrix (without cracks) upon shrinkage (Cornelis et al., 2006), which is of particular interest for modelling infiltration of water. This approach is different from in situ measurements, such as those conducted by Cabidoche and Voltz (1995) who studied volume changes of bulk soil volumes (including cracks). A further advantage of the paraffincoated method is that the samples are undisturbed and unconfined and the measurement error is low. A disadvantage of the method is that distinct samples are required per SSCC data pair, which is time consuming. The widely-used core method of Berndt and Coughlan (1976) also uses undisturbed soil samples, and is easy to use and not labour intensive. It further allows determining the SSCC using one single soil sample. However, it is subject to boundary conditions as confined cores are used and the measuring error can be rather high. The balloon method of Tariq and Durnford (1993a) is also easy to use, non-time consuming and needs a single soil sample only. In our study, the latter was unconfined but disturbed, though undisturbed cores can be used as well. Comparing the two latter methods with the paraffin method allows us to address the question whether using a core produces data as good as an undisturbed unconfined clod, and whether the destruction of the soil macrostructure does not matter, which would enable us to use an easier and more reproducible method.

\section{Description of the selected SSCC models}

It should be noted first that all models described here are expressed in terms of the void ratio as a function of the moisture ratio, which are respectively the volume of voids and the volume of water over the volume of solids. We therefore had to rewrite some of the models compared to their original notation reported in literature.

\subsection{The model of Giráldez et al. (1983) - Gea model}

The equation of Sposito and Giráldez (1976) obeys the Law of Corresponding States which relates the specific volume of a soil, i.e. the volume of voids per unit mass of solids, to the gravimetric water content. It was adapted by Giráldez and Sposito (1983) and Giráldez et al. (1983) who used a third order polynomial function for their 'universal' SSCC. When converting their model (further denoted here as the Gea model) to express the void ratio $e$ versus the moisture ratio $\vartheta$, we can rewrite it as:

$e=0.7429 \varphi \vartheta_{\mathrm{B}}+0.230 \frac{\varphi}{\vartheta_{\mathrm{B}}} \vartheta^{2}+0.0267 \frac{\varphi}{\vartheta_{\mathrm{B}}^{2}} \vartheta^{3}$

where $\vartheta_{\mathrm{B}}$ is the moisture ratio at air entry and $\varphi$ is the slope of the saturation line. Eq. (2) is only valid to describe the zero, residual and normal shrinkage stages of the SSCC, since it only shows a minimum and no maximum (McGarry and Malafant, 1987). Note that Eq. (2) contains one parameter less than the original model of Giráldez et al. (1983) and Giráldez and Sposito (1983), which included the specific volume of the solids. The latter becomes zero when converted to void ratio. The Gea model hence contains two parameters only. 


\subsection{The "three straight lines" model of McGarry and Malafant (1987) - MM1 model}

Rather than using a continuous polynomial function as Eq. (2), McGarry and Malafant (1987) proposed using linear curves for the three distinct shrinkage stages of the SSCC, being residual, normal and structural shrinkage. Using the general relationship given by Newman and Thomasson (1979), and making the conversion to express $e$ vs. $\vartheta$, their "three straight lines model" can be written as (MM1 model):

$$
\begin{array}{ll}
e=e_{0}+\frac{\vartheta}{\vartheta_{\mathrm{B}}}\left(\vartheta_{\mathrm{B}}-e_{0}+e_{\mathrm{n}}\right) & \text { for } 0<\vartheta<\vartheta_{\mathrm{B}} \\
e=e_{\mathrm{n}}+\vartheta_{\mathrm{S}} & \text { for } \vartheta_{\mathrm{B}}<\vartheta<\vartheta_{\mathrm{C}} \\
e=e_{\mathrm{S}}+\frac{\vartheta}{\vartheta_{\mathrm{C}}}\left(\vartheta_{\mathrm{C}}-e_{\mathrm{S}}+e_{\mathrm{n}}\right) & \text { for } \vartheta_{\mathrm{C}}<\vartheta<\vartheta_{\mathrm{D}}
\end{array}
$$

where $\vartheta_{\mathrm{C}}$ is the swelling limit moisture ratio, $\vartheta_{\mathrm{D}}$ is the maximum moisture ratio, $e_{0}$ is the void ratio at zero moisture ratio, $e_{\mathrm{n}}$ is the constant void ratio of air filled pores and equal to the difference between the void ratio and the moisture ratio in the normal shrinkage zone, and $e_{\mathrm{s}}$ is the intercept of the structural shrinkage curve. The MM1 model contains five parameters.

\subsection{The logistic model of McGarry and Malafant (1987) - MM2 model}

Because many SSCC data sets show an "S" shape, McGarry and Malafant (1987) further presented a generalized logistic model (Nelder, 1961, 1962) containing four parameters to describe the SSCC (MM2 model):

$e=e_{0}+\frac{e_{\mathrm{v}}}{1+\exp \left[-\beta\left(\vartheta-\vartheta_{\mathrm{i}}\right)\right]}$

where $e_{\mathrm{v}}$ is the maximum void ratio range, equal to the void ratio at saturation $e_{\mathrm{D}}$ minus the void ratio at oven dryness $e_{0}, \beta$ is a slope parameter depending on the air entry value, and $\vartheta_{\mathrm{i}}$ is the moisture ratio at the inflection point. The void ratio at zero moisture ratio $e_{0}$ represents the lower asymptote, whereas $e_{\mathrm{D}}=e_{0}+e_{\mathrm{v}}$ is the upper asymptote. Although some physical meaning can be given to the parameters in Eq. (4), the MM2 model has, in contrast with Eqs. (2) and (3), no theoretical basis. The model should, however, be valid over the complete SSCC, including all four stages.

\subsection{The model of Kim et al. (1992) - Kea model}

Kim et al. (1992) combined an exponential and linear function which gave best fits to their data. Their three-parameter model is currently used in the soil-water and solute transport computer simulation model SWAP (van Dam et al., 1997) and was written as (Kea model):

$e=e_{0} \exp (-\beta \vartheta)+\varphi \vartheta$

where the model parameters are as described above. As for the Gea model, the Kea model does not consider structural shrinkage.
The theory behind the model is restricted to the representation of the normal shrinkage by a linear function, and by expressing the zero and residual shrinkage by an inverse exponential function which gradually approaches to a certain denominator value as the moisture ratio decreases (Kim et al., 1992).

\subsection{The model of Tariq and Durnford (1993b) - TD model}

Tariq and Durnford (1993b) introduced a seven-parameter analytical model which was derived using theoretical boundary or other conditions that are inherent to the definitions of the SSCC stages. It is an extension of the MM1 model and considers all four shrinkage stages. It was defined as (TD model):

$\begin{array}{ll}e=e_{0} & \text { for } 0<\vartheta<\vartheta_{\mathrm{A}} \\ e=a_{0}+a_{1} \vartheta+a_{2} \vartheta^{2}+a_{3} \vartheta^{3} & \text { for } \vartheta_{\mathrm{A}}<\vartheta<\vartheta_{\mathrm{B}} \\ e=e_{\mathrm{B}}-\vartheta_{\mathrm{B}}+\vartheta & \text { for } \vartheta_{\mathrm{B}}<\vartheta<\vartheta_{\mathrm{C}} \\ e=\vartheta_{0}+c_{1} \vartheta+c_{2} \vartheta^{2} & \text { for } \vartheta_{\mathrm{C}}<\vartheta<\vartheta_{\mathrm{D}}\end{array}$

where the coefficients, as derived from the boundary conditions, are defined as:

$$
\begin{aligned}
& a_{0}=e_{0}+\frac{A}{2} \vartheta_{\mathrm{A}}^{2}+\frac{B}{3} \vartheta_{\mathrm{A}}^{3} \\
& a_{1}=-A \vartheta_{\mathrm{A}}-\frac{B}{2} \vartheta_{\mathrm{A}}^{2} \\
& a_{2}=\frac{A}{2} \\
& a_{3}=\frac{B}{6} \\
& c_{0}=e_{\mathrm{C}}-\vartheta_{\mathrm{C}}+\frac{C}{2} \vartheta_{\mathrm{C}}^{2} \\
& c_{1}=1-C \vartheta_{\mathrm{C}} \\
& c_{2}=\frac{C}{2} \\
& A=\frac{1}{\vartheta_{\mathrm{B}}-\vartheta_{\mathrm{A}}}-\frac{B}{2}\left(\vartheta_{\mathrm{B}}+\vartheta_{\mathrm{A}}\right)
\end{aligned}
$$

and $e_{\mathrm{B}}$ and $e_{\mathrm{C}}$ are the void ratio at respectively air entry (in the intra-aggregate pores) and the swelling limit.

\subsection{The model of Olsen and Haugen (1998) - OH model}

In addressing the prerequisite suggested by Philip (1969) and Sposito (1973) that the slope of the shrinkage curve should increase monotonically from 0 to 1 , when moving from zero to normal shrinkage, Olsen and Haugen (1998) proposed a second order hyperbolic equation. Using its positive solution to represent the SSCC between zero shrinkage and basic shrinkage, and its negative solution to describe the SSCC from basic to structural shrinkage, they defined their SSCC as (OH model):

$$
\begin{aligned}
& e=\frac{1}{2}\left[\varphi \vartheta+e_{0}+\sqrt{\left(\varphi \vartheta+e_{0}\right)^{2}-4 e_{0}(1-\eta) \vartheta}\right] \text { for } \vartheta \leq \vartheta_{\mathrm{t}} \\
& e=\Delta\left(\vartheta_{\mathrm{t}}\right)+\frac{1}{2}\left[\varphi \vartheta+\varepsilon+\sqrt{(\varphi \vartheta+\varepsilon)^{2}-4 \varepsilon(1-\lambda) \vartheta}\right] \text { for } \vartheta>\vartheta_{\mathrm{t}}
\end{aligned}
$$

where $\eta$ reflects the curvature at the transition zones between residual and normal shrinkage, $\lambda$ reflects the 
curvature at the transition zones between normal and structural shrinkage, $\varepsilon$ is a coefficient depending on the upper asymptote, and $\vartheta_{\mathrm{t}}$ is a threshold moisture ratio where the two domains of the SSCC join. The $\mathrm{OH}$ model contains six parameters.

\subsection{The model of Braudeau et al. (1999) — Bea model}

Braudeau et al. (1999) suggested a seven-parameter model similar to the TD model, but they represented the curvilinear zones by exponential equations rather than polynomials. They further divided the structural zone into a linear and curvilinear zone, including a point of friability. Their model was defined as (Bea model):

$\begin{array}{ll}e=e_{\mathrm{A}}+\left(e_{\mathrm{A}}-e_{0}\right) \vartheta_{\mathrm{OA}} & \text { for } 0<\vartheta<\vartheta_{\mathrm{A}} \\ e=e_{\mathrm{A}}+\left(e_{\mathrm{B}}-e_{\mathrm{A}}\right) \frac{K_{\mathrm{BC}}\left[\exp \left(\vartheta_{\mathrm{AB}}\right)-\vartheta_{\mathrm{AB}}-1\right]+K_{0 \mathrm{~A}}\left[2.1718 \vartheta_{\mathrm{AB}}-\exp \left(\vartheta_{\mathrm{AB}}\right)+1\right]}{0.718 K_{\mathrm{BC}}+K_{0 \mathrm{~A}}} & \text { for } \vartheta_{\mathrm{A}}<\vartheta<\vartheta_{\mathrm{B}} \\ e=e_{\mathrm{B}}+\left(e_{\mathrm{C}}-e_{\mathrm{B}}\right) \vartheta_{\mathrm{BC}} & \text { for } \vartheta_{\mathrm{B}}<\vartheta<\vartheta_{\mathrm{C}} \\ e=e_{\mathrm{D}}+\left(e_{\mathrm{C}}-e_{\mathrm{D}}\right) \frac{K_{\mathrm{BC}}\left[\exp \left(\vartheta_{\mathrm{CD}}\right)-\vartheta_{\mathrm{CD}}-1\right]+K_{\mathrm{DS}}\left[2.1718 \vartheta_{\mathrm{CD}}-\exp \left(\vartheta_{\mathrm{CD}}\right)+1\right]}{0.718 K_{\mathrm{BC}}+K_{\mathrm{DS}}} & \text { for } \vartheta_{\mathrm{C}}<\vartheta<\vartheta_{\mathrm{D}} \\ e=e_{\mathrm{D}}+\left(e_{\mathrm{S}}-e_{\mathrm{D}}\right) \vartheta_{\mathrm{DS}} & \text { for } \vartheta_{\mathrm{D}}<\vartheta<\vartheta_{\mathrm{S}}\end{array}$

where

$\vartheta_{\mathrm{IJ}}=\frac{\vartheta-\vartheta_{\mathrm{I}}}{\vartheta_{\mathrm{J}}-\vartheta_{\mathrm{I}}}$

The slopes of the linear curves are:

$\begin{aligned} K_{\mathrm{OA}} & =\frac{e_{\mathrm{A}}-e_{0}}{\vartheta_{\mathrm{A}}} \\ K_{\mathrm{BC}} & =\frac{e_{\mathrm{B}}-e_{\mathrm{C}}}{\vartheta_{\mathrm{B}}-\vartheta_{\mathrm{C}}} \\ K_{\mathrm{DS}} & =\frac{e_{\mathrm{D}}-e_{\mathrm{S}}}{\vartheta_{\mathrm{D}}-\vartheta_{\mathrm{S}}}\end{aligned}$

3.8. The modified model of Chertkov (2000, 2003) - ModC model

Chertkov $(2000,2003)$ proposed an expression based on the statistical analogy between crack networks (Chertkov and Ravina, 1998) and the probabilistic microstructure of a matrix consisting only of clay particles. His SSCC can be represented as:

$$
\begin{aligned}
& e=e_{0} \quad \text { for } 0<\vartheta<\vartheta_{\mathrm{A}} \\
& e=e_{0}+\mu\left(\vartheta-\vartheta_{\mathrm{A}}\right)^{2} \frac{\rho_{\mathrm{w}}^{2}}{\rho_{\mathrm{s}}} \quad \text { for } \vartheta_{\mathrm{A}}<\vartheta<\vartheta_{\mathrm{B}} \\
& e=\vartheta \quad \text { for } \vartheta_{\mathrm{B}}<\vartheta<\vartheta_{\mathrm{L}}
\end{aligned}
$$

where $\mu$ is a model coefficient, $\rho_{\mathrm{w}}$ is the density of water, $\rho_{\mathrm{s}}$ is the density of the solid particles, and $\vartheta_{\mathrm{L}}$ is the liquid limit, which is the maximum moisture ratio in the solid state of the clay, or at which the shear strength approaches that of a liquid. Since the Chertkov $(2000,2003)$ model was developed for a matrix of clay particles only, the SSCC in the normal shrinkage zone was considered to be equal to the load line, i.e. a SSCC with unit slope and zero intercept. In order to evaluate the potential behaviour of the Chertkov $(2000,2003)$ model for soils in general, we have modified the normal shrinkage part of the model to (ModC model):

$e=2 \mu\left(\vartheta_{\mathrm{B}}-\vartheta_{\mathrm{A}}\right) \vartheta+\sigma \quad$ for $\vartheta_{\mathrm{B}}<\vartheta<\vartheta_{\mathrm{L}}$

where $\sigma$ is the intercept of the SSCC in the normal (or more correctly, the proportional) shrinkage zone. We could then write the intercept as:

$\sigma=e_{0}-\mu\left(\vartheta_{\mathrm{B}}-\vartheta_{\mathrm{A}}\right)\left(\vartheta_{\mathrm{B}}+\vartheta_{\mathrm{A}}\right)$

The slope of Eq. (10) follows from the conditions that ensure continuity of the equations. The ModC model contains four parameters.

\subsection{The simplified model of Groenevelt and Grant (2001, 2002) (Cornelis et al., 2006) - ModGG model}

Groenevelt and Grant (2001, 2002) used Groenevelt and Bolt's (1972) theoretical equation describing the moisture ratio as a function of the void ratio under different load pressures, to express their SSCC for unloaded soil. Their model can be written as:

$e=e_{\mathrm{S}}+\gamma\left[\exp \left(\frac{-\xi}{\vartheta^{\zeta}}\right)-\exp \left(\frac{-\xi}{e_{\mathrm{S}}^{\zeta}}\right)\right]$

where $\gamma, \xi$ and $\zeta$ are model parameters. The model of Groenevelt and Grant (2001, 2002) covers all four shrinkage stages. It was rewritten by Cornelis et al. (2006) as (ModGG model):

$e=e_{0}+\gamma\left[\exp \left(\frac{-\xi}{\vartheta^{\zeta}}\right)\right]$

Note that $e=e_{0}$ for $\vartheta=0$. The ModGG model contains four parameters.

\section{Materials and methods}

\subsection{Soil sampling and soil properties}

The study was based on soil samples taken from seven horizons of a Eutric Vertisol and a Ferri-Gleyic Lixisol (WRB, 1998) under sugar cane in the Havana province, Cuba. In the Vertisol, A and B horizons were distinguished within the upper $1.5 \mathrm{~m}$ of the soil profile. The B horizon was further divided into three subhorizons (B1, B2 and B3). The A horizon had a blocky structure and showed a strong vertical shrinkage behaviour, though there was also evidence of less pronounced horizontal shrinkage. Slickensides did occur at its lower boundary. The B1, B2 and B3 horizons were characterized by respectively a moderate, high and very high density of slickensides and they were structureless (massive). Root density was high in the A horizon and low in the B1 horizon. Roots were absent in horizon B2 and B3. The Lixisol showed an A, B and C horizon within the upper $1.5 \mathrm{~m}$ of the soil profile. The $\mathrm{A}$ and $\mathrm{B}$ horizon had a crumbly and fine crumbly structure respectively, whereas 
Table 1

Physicochemical properties of the Vertisol and the Lixisol

\begin{tabular}{|c|c|c|c|c|c|c|c|c|c|c|}
\hline Horizon & Depth $(\mathrm{cm})$ & Clay $\left(\mathrm{g} \mathrm{kg}^{-1}\right)$ & Silt $\left(\mathrm{g} \mathrm{kg}^{-1}\right)$ & Sand $\left(\mathrm{g} \mathrm{kg}^{-1}\right)$ & $\mathrm{OC}\left(\mathrm{g} \mathrm{kg}^{-1}\right)$ & $\mathrm{CaCO}_{3}\left(\mathrm{~g} \mathrm{~kg}^{-1}\right)$ & $\mathrm{CEC}\left(\mathrm{cmol}(+) \mathrm{kg}^{-1}\right)$ & $V_{\mathrm{b}}(\%)$ & $\mathrm{EC}_{\mathrm{e}}\left(\mathrm{dS} \mathrm{m} \mathrm{m}^{-1}\right)$ & COLE \\
\hline $\mathrm{V}-\mathrm{A}$ & $0-20$ & 791 & 140 & 69 & 18.4 & 29.3 & 46.3 & 100 & 0.77 & 0.127 \\
\hline $\mathrm{V}-\mathrm{B} 1$ & $20-61$ & 777 & 126 & 97 & 3.1 & 13.3 & 47.6 & 85.6 & 2.73 & 0.134 \\
\hline $\mathrm{V}-\mathrm{B} 2$ & $61-110$ & 813 & 115 & 72 & 2.5 & 35.9 & 40.1 & 100 & 4.58 & 0.121 \\
\hline $\mathrm{V}-\mathrm{B} 3$ & $110-150$ & 813 & 132 & 55 & 1.6 & 23.6 & 39.4 & 100 & 4.34 & 0.097 \\
\hline $\mathrm{L}-\mathrm{A}$ & $0-40$ & 764 & 169 & 67 & 24.2 & 8.0 & 27.5 & 79.5 & 1.13 & 0.076 \\
\hline $\mathrm{L}-\mathrm{B}$ & $40-90$ & 882 & 83 & 35 & 4.3 & 5.3 & 18.4 & 83.9 & 0.71 & 0.061 \\
\hline $\mathrm{L}-\mathrm{C}$ & $90-130$ & 839 & 113 & 48 & 3.1 & 8.0 & 18.9 & 78.5 & 0.69 & 0.050 \\
\hline
\end{tabular}

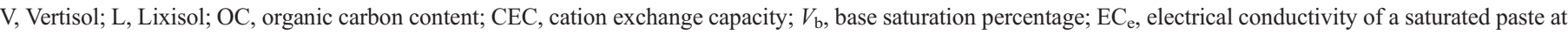
$25{ }^{\circ} \mathrm{C}$.

the $\mathrm{C}$ horizon was structureless. Root development was high and very high in the A and $\mathrm{B}$ horizon respectively, but low in the $\mathrm{C}$ horizon. Table 1 summarizes some of the physicochemical properties of both soils. They were very high in clay content, but differed substantially in their swelling and shrinking potential, expressed in terms of the COLE index (Grossman et al., 1968):

$\operatorname{COLE}=\frac{z_{\mathrm{w}}}{z_{\mathrm{d}}}-1$

where $z_{\mathrm{w}}$ is the length of a wet soil sample at $-33 \mathrm{kPa}$ and $z_{\mathrm{d}}$ is the length of an oven-dry soil sample. The Vertisol showed a very strong swelling and shrinking potential (Soil Conservation Service, 1972), with a COLE index ranging from 0.097 to 0.134 . The swelling and shrinking potential of the Lixisol was moderate to strong, with a COLE index between 0.050 and 0.076. These differences in shrinkage properties of both soils are reflected by the soil's cation exchange capacity (CEC). Values in the order of $40 \mathrm{cmol} \mathrm{kg}{ }^{-1}$ suggest a dominance of $2: 1$ clay minerals such as smectites, whereas values between 10 and $40 \mathrm{cmol} \mathrm{kg}^{-1}$ indicate micas as the prevailing clay mineral (Jury et al., 1991).

\subsection{Methods to assess the SSCC}

To determine the SSCC with the method of Berndt and Coughlan (1976) which directly measures the dimensions of the soil sample, undisturbed $100-\mathrm{cm}^{3}$ soil samples were taken using Kopecki rings in three replicates from each horizon. Samples were taken under almost saturated conditions and were allowed to wet by capillary rise for four weeks. The samples were then dried at about $60 \%$ relative humidity and a temperature of $20{ }^{\circ} \mathrm{C}$. The mass, height and diameter of the cylindrical soil samples were measured daily using an electronic balance and a vernier calliper with a measuring accuracy of $0.05 \mathrm{~mm}$ for two and a half weeks in total. Finally, the samples were oven-dried at $105{ }^{\circ} \mathrm{C}$ and gravimetric water content was determined.

The balloon method of Tariq and Durnford (1993a) was applied on 50 to $70 \mathrm{~g}$ disturbed soil samples from the seven horizons and sieved at $2 \mathrm{~mm}$. They were air-dried and then poured into a rubber balloon. Water was then added and the balloon was closed using a hard rubber stopper. The water and soil filled balloon was put aside for four days to allow saturation. The sample was unconfined because of the elasticity of the balloon. The stopper was then replaced with another one with a plastic air inlet and outlet which could be closed with a valve. To allow drying, both valves were kept open and the air inlet was connected to an air pump which passed air with low pressure over the sample (ca. $20 \mathrm{kPa}$ or 50 to $100 \mathrm{~L}$ per hour). Water was taken up by the air flow and was removed through the air outlet. At regular time intervals of ca. $12 \mathrm{~h}$, the volume and mass of the samples were measured. To determine the volume, the valves were closed and a small vacuum was applied to ensure a perfect fitting of the balloon to the soil sample. The balloon was then attached to a stand using a hanging hook and was lowered into a beaker of water which was placed on an electronic balance. This allowed measuring the mass of water replaced by the soil sample using the Archimedes principle. The mass of the sample was determined directly by weighing it on the electronic balance. The complete drying process took about two weeks and the soil sample was then ovendried at $105{ }^{\circ} \mathrm{C}$. Increasing the pressure of the air could significantly reduce the duration of the drying process. Using small soil samples with a destroyed macrostructure ensured that crack formation within the soil mass was prevented. The complete setup is shown in Fig. 2. It can be easily constructed; we used e.g. a simple aquarium pump to create an air flow.

Finally, the paraffin-coated method suggested by Lauritzen and Stewart (1941) was applied on a limited number of soil clods from the four Vertisol horizons. The clods were obtained by breaking small soil samples by hand after they had been subjected

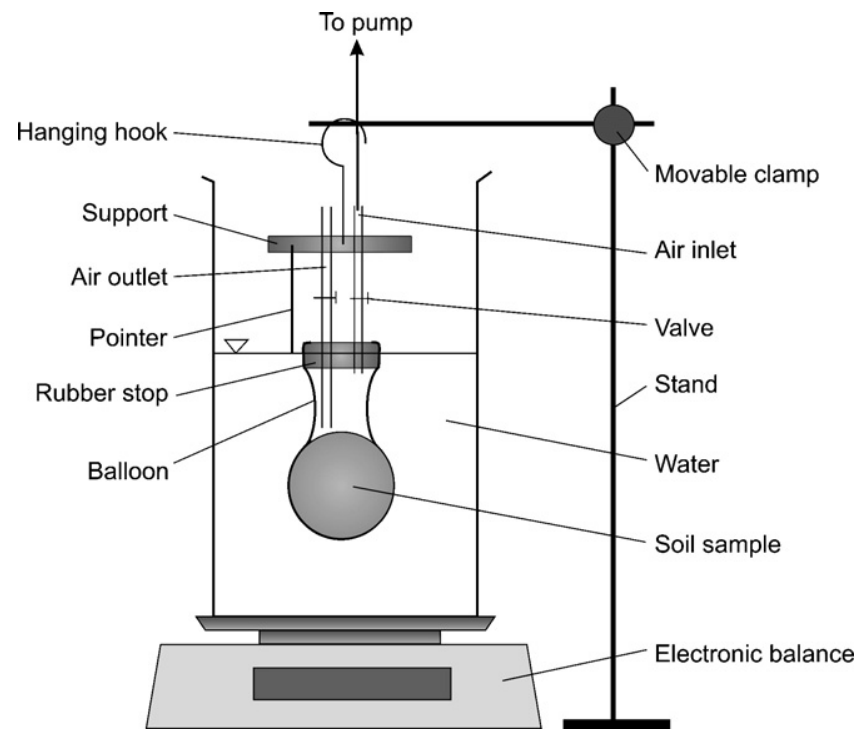

Fig. 2. Experimental setup to determine the soil shrinkage characteristic curve according to the balloon method of Tariq and Durnford (1993a). 

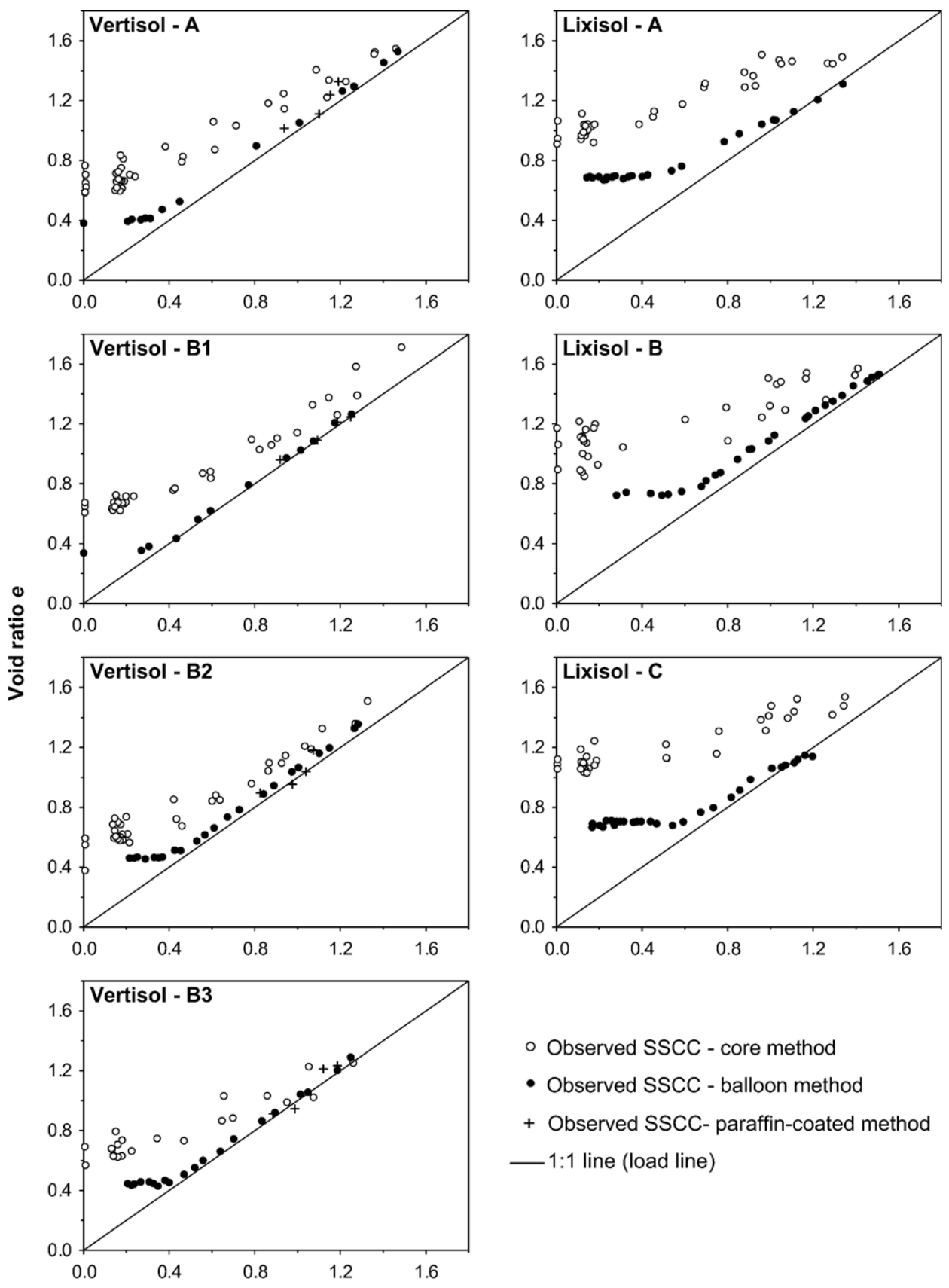

- Observed SSCC - core method

- Observed SSCC - balloon method

+ Observed SSCC- paraffin-coated method

- $1: 1$ line (load line)

\section{Moisture ratio $\vartheta$}

Fig. 3. Observed soil shrinkage characteristic curves determined with the core method (Berndt and Coughlan, 1976) and the balloon method (Tariq and Durnford, 1993a). A, B, B1, B2, B3, C refer to the soil horizons.

to a matric potential of $-20,-33,-100$ and $-1500 \mathrm{kPa}$ in pressure chambers (Soilmoisture Equipment, Santa Barbara CA, USA) to subject the soil sample to shrinkage. This procedure limited the number of microcracks present in the clods, since the latter were broken along the microcracks formed in the samples. The separated clods were then submerged in paraffin melted at $40{ }^{\circ} \mathrm{C}$ with a density of $0.902 \mathrm{Mg} \mathrm{m}^{-3}$. After cooling the samples, they were submerged in water. The volume was determined by the Archimedes principle. In order to compare the void ratios obtained using the paraffin method and make them correspond to the above matric potentials with the void ratios of the core and balloon method, the latter were calculated using respectively the MM2 and the MM1 model (Corluy, 2001) in combination with the soil-water retention curve.

\subsection{Data analysis}

Gravimetric water content was converted to the moisture ratio using:

$\vartheta=w \frac{\rho_{\mathrm{s}}}{\rho_{\mathrm{w}}}$ 
where $w$ is the gravimetric water content. The density of the solids $\rho_{\mathrm{s}}$ was determined using a water pycnometer. The void ratio was calculated as:

$e=\frac{\rho_{\mathrm{s}}}{\rho_{\mathrm{b}}}-1$

where $\rho_{\mathrm{b}}$ is the bulk density.

The model parameters were obtained by fitting the models to the observed SSCC using a conjugant-gradient algorithm (Press et al., 1992) in MathCad ${ }^{\circledR}$. In order to prevent convergence of SSE in local minima in the objective function, the program was routinely rerun with different initial parameter estimates. Constraints such as e.g. $\vartheta_{\mathrm{A}} \leq \vartheta_{\mathrm{B}}$ were introduced when appropriate.

To assess the 'goodness-of-fit' of the models, we have calculated for each soil sample the root of the mean of squared errors RMSE, the coefficient of determination $R^{2}$, and the Akaike Information Criterion AIC (Akaike, 1974). The AIC combines the SSE with the number of model parameters. The "best" model is the one which minimizes the AIC, or in other words, which combines the lowest SSE value with the lowest number of model parameters. Although computers can nowadays easily handle models with many parameters, limiting the number of parameters is of particular interest when attempting to predict the SSCC from readily available data using pedotransfer functions. In order to facilitate the comparison between the different expressions, the mean of RMSE, of $R^{2}$ and of AIC was calculated over all soil samples for each expression. A $t$-test was performed to examine whether the computed means were significantly different at the 0.05 level.

\section{Results and discussion}

\subsection{Assessment of the SSCC}

In Fig. 3, the SSCCs determined using the core method of Berndt and Coughlan (1976), the balloon method of Tariq and Durnford (1993a) and the paraffin-coated method of Lauritzen and Stewart (1941) are compared for the seven horizons considered in this study. Larger void ratios indicating less shrinkage can be observed when comparing the core method with the balloon and paraffin-coated method, except for water contents near saturation. This was also observed by Crescimanno and Provenzano (1999) when comparing the core method (Berndt and Coughlan, 1976) with the resin-coated aggregates method (Brasher et al., 1966). There exist three possible explanations for the apparently less pronounced shrinkage behaviour when applying the core method. First, Crescimanno and Provenzano (1999) attributed this behaviour to the shrinkage being anisotropic rather than isotropic which is assumed when using the core method. The anisotropic shrinkage could to some extent be due to the confining action of the cores. They are constrained boundaries causing one-dimensional rather than isotropic swelling when the samples, which were taken under soil-water conditions lower than saturation, are saturated. The anisotropic shrinkage is supported by the observed variation of the geometry factor, which ranged be- tween 1.1 and 5.2 for the Vertisol and 1.0 and 4.8 for the Lixisol. As an example, Fig. 4 shows $r_{\mathrm{s}}$ to increase gradually with decreasing $\vartheta$ for horizon B1 of the Vertisol. An $r_{\mathrm{s}}$ value near unity results from the shrinkage process being controlled only by a vertical downward movement of soil particles due to gravity (Kim et al., 1992). With further drying, the soil becomes stable and the horizontal shrinkage component increases resulting in a three dimensional shrinkage. Second, Crescimanno and Provenzano (1999) considered that the reorientation of particles caused by shear stresses along the sample wall which occurs during sampling could have been another factor preventing the confined cores from obtaining the minimum possible configuration and volume. A third and most probable explanation is the occurrence of small cracks in the undisturbed samples, which was also assumed by Tariq and Durnford (1993a) when comparing the results obtained with the resincoating method and their balloon method. This explanation is further supported by Bruand and Prost (1987) who studied the shrinkage behaviour of a Luvisol on differently-sized soil samples, including a paste prepared from particles for which $65 \%$ were $<20 \mu \mathrm{m}$ in size, and aggregates with a volume of $0.03 \mathrm{~cm}^{3}, 3 \mathrm{~cm}^{3}$ and $300 \mathrm{~cm}^{3}$, using the kerosene method. They found pore volume to increase in the normal and residual shrinkage stage with increasing aggregate size, and attributed it to the opening of small, 'millimetric' cracks in those aggregates. Aggregates are build up from several millimetric domains and the number of these domains increases with aggregate size. The number of millimetric cracks enclosing the millimetric domains therefore increases with the size of the sample. Since we used, when applying the balloon method, disturbed soil with aggregates $<2 \mathrm{~mm}$, cracks were probably not formed. In the paraffin-coated method, the number of microcracks was also minimal because we separated the clods from the undisturbed soil samples after they were subjected to shrinkage. The difference between the core method on one hand, and the balloon and paraffin-coated methods on the other is further most pronounced for the Lixisol. The latter was more structured at all horizons compared with the more massive Vertisol, and is therefore more susceptible to the processes associated with the above explanations.

In addition to differences in shrinkage behaviour between the core method and the balloon method, the core method also

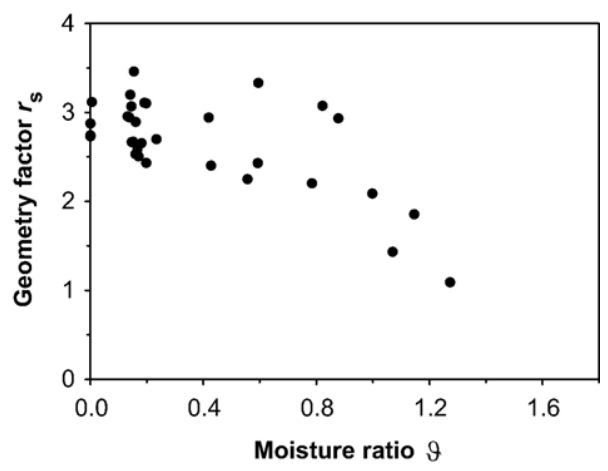

Fig. 4. The geometry factor $r_{\mathrm{s}}$ as a function of the moisture ratio $\vartheta$ for the B1 horizon of the Vertisol. 
showed much higher scatter (see Fig. 3). This is reflected as well in Fig. 5 showing the residuals associated with both methods when fitting the ModGG model (Cornelis et al., 2006) to the data. Residuals were not computed for the paraffin-coated method since the range and number of data pairs per SSCC were too limited for fitting the ModGG model (see Fig. 3). The higher scatter can be mainly attributed to physical errors in measuring the volume of the soil cores (Tariq and Durnford, 1993a). Measuring the volume of the soil samples at the different drying stages was more accurate by submergence and application of Archimedes' law compared with measurement of length and diameter with a vernier calliper. This is due to the shape of the undisturbed core samples not being perfectly cylindrical and the reading error of the vernier calliper. The precision of the vernier calliper used was $0.05 \mathrm{~mm}$ and a small error in measuring the core height and diameter results in relatively large errors in the calculated volume. Higher precision measurements could be obtained when using the retractometer of Braudeau et al. (1999). Furthermore, as the cores dried out, small cracks were formed and crumbling of small soil aggregates was observed at the extremes of the soil sample. This was most pronounced on those samples that were collected from the structured horizons, i.e. V-A with a blocky structure, and $\mathrm{L}-\mathrm{A}$ and $\mathrm{L}-\mathrm{B}$, which showed a crumbly structure. The $\mathrm{V}-\mathrm{B}$ samples were structureless and shrank more massively. The effect of structure on the scatter on the SSCC data is also reflected in the residuals associated with the different horizons when fitting the ModGG model (Cornelis et al., 2006) to the core method data, as illustrated in Fig. 5.

When comparing the void ratio obtained from the core and balloon method with the void ratio from the reference paraffincoated method, a very good agreement between the results of the paraffin-coated and balloon method can be observed (Fig. 6). This could further indicate that the balloon method, though not physically realistic as it uses sieved soil, is more accurate and reliable than the core method for measuring the shrinkage

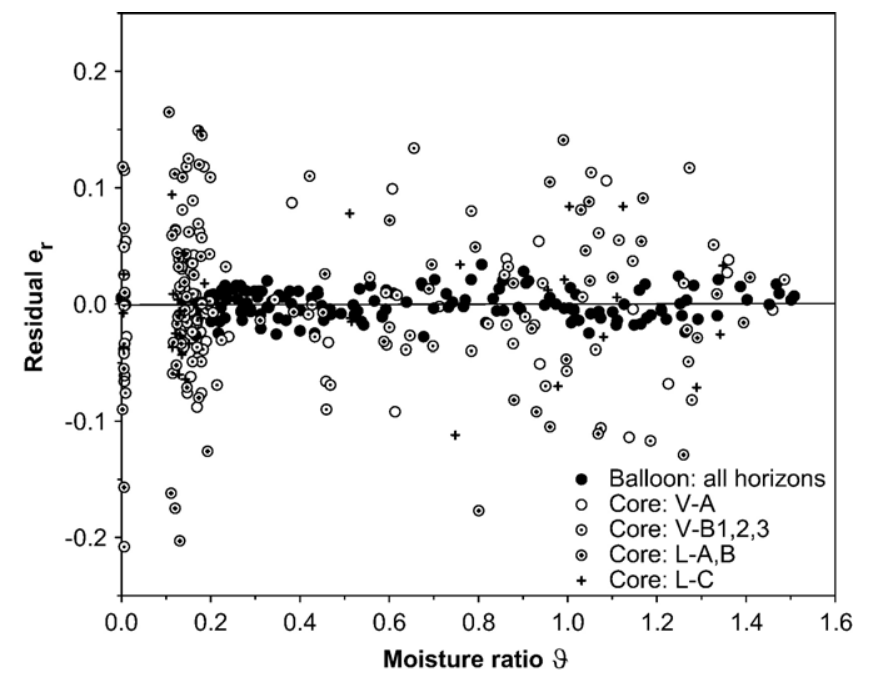

Fig. 5. The residuals $e_{\mathrm{r}}$ associated with the core method (Berndt and Coughlan, 1976) and the balloon method (Tariq and Durnford, 1993a) for different horizons as a function of the moisture ratio $\vartheta$. V-A, V-B1, 2, 3, L-A,B and L$\mathrm{C}$ refer to the different horizons of the Vertisol, $\mathrm{V}$, and the Lixisol, L.

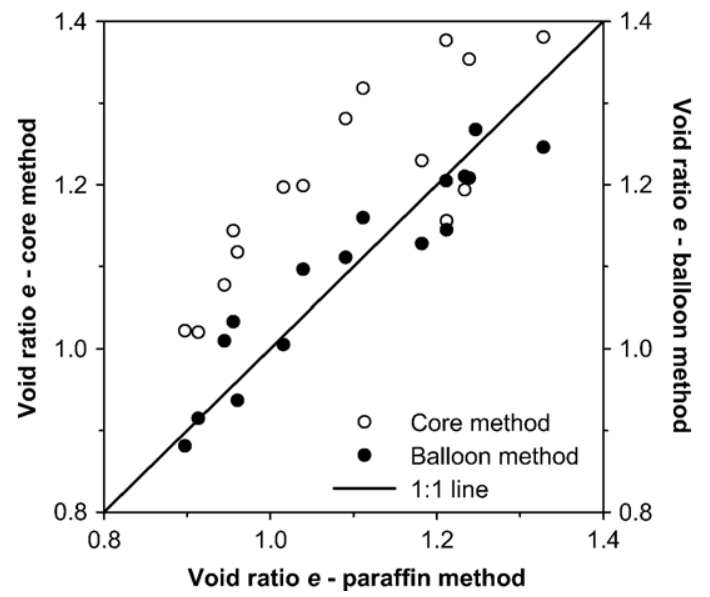

Fig. 6. The void ratio $e$ measured with the core method (Berndt and Coughlan, 1976) and the balloon method (Tariq and Durnford, 1993a) vs. the void ratio $e$ measured with the paraffin-coated method (Lauritzen and Stewart, 1941).

behaviour at the scale of the soil matrix without cracks. Given that the balloon method is easy to use and non-labour intensive, and that it provides well reproducible data using one single sample only, it is a good alternative for the paraffin-coated method. However, an advantage of the core method is that it allows determining the geometry factor which was shown to change with moisture ratio.

\subsection{Modelling the SSCC}

Table 2 shows the values of the validation indices which were computed to compare the nine models in terms of their accuracy and reliability. When considering the mean of RMSE and $R^{2}$ and the test statistics, three groups of similar performance can be distinguished. A first group with lowest mean RMSE and highest mean $R^{2}$ values included the Bea, MM1, ModC and ModGG models (cfr. letter ' $a$ ' in Table 2). Intermediate results were obtained with the MM2, TD, OH and Kea models (cfr. letters 'ab' and 'b'). The Gea model showed the lowest performance ( $\mathrm{cfr}$. letter ' $\mathrm{c}$ '). A relatively poor

Table 2

Mean values of the validation indices computed for the tested models ${ }^{\mathrm{a}}$

\begin{tabular}{llll}
\hline Model & RMSE & $R^{2}$ & AIC \\
\hline Gea & $0.041 \mathrm{c}^{\mathrm{b}}$ & $0.979 \mathrm{c}$ & $-19.65 \mathrm{c}$ \\
MM1 & $0.011 \mathrm{a}$ & $0.998 \mathrm{a}$ & $-37.93 \mathrm{ab}$ \\
MM2 & $0.020 \mathrm{~b}$ & $0.995 \mathrm{~b}$ & $-28.81 \mathrm{abc}$ \\
Kea & $0.021 \mathrm{~b}$ & $0.991 \mathrm{ab}$ & $-27.49 \mathrm{bc}$ \\
TD & $0.014 \mathrm{a}$ & $0.995 \mathrm{ab}$ & $-29.00 \mathrm{abc}$ \\
OH & $0.016 \mathrm{ab}$ & $0.995 \mathrm{ab}$ & $-29.64 \mathrm{abc}$ \\
Bea & $0.011 \mathrm{a}$ & $0.998 \mathrm{a}$ & $-34.35 \mathrm{ab}$ \\
ModC & $0.011 \mathrm{a}$ & $0.998 \mathrm{a}$ & $-39.13 \mathrm{a}$ \\
ModGG & $0.012 \mathrm{a}$ & $0.998 \mathrm{a}$ & $-36.10 \mathrm{ab}$ \\
\hline
\end{tabular}

a RMSE, root of mean squared errors; AIC, Akaike Information Criterion; Gea, Giráldez et al.; MM1, McGarry and Malafant — model 1; MM2, McGarry and Malafant - model 2; Kea, Kim et al.; TD, Tariq and Durnford; OH, Olsen and Haugen; Bea, Braudeau et al.; ModC, Modified Chertkov; ModGG, Modified Groenevelt and Grant.

b Values with same letter are not significantly different at $P=0.05$; the letter ' $a$ ' indicates highest performance, ' $b$ ' moderate, and 'c' lowest. 

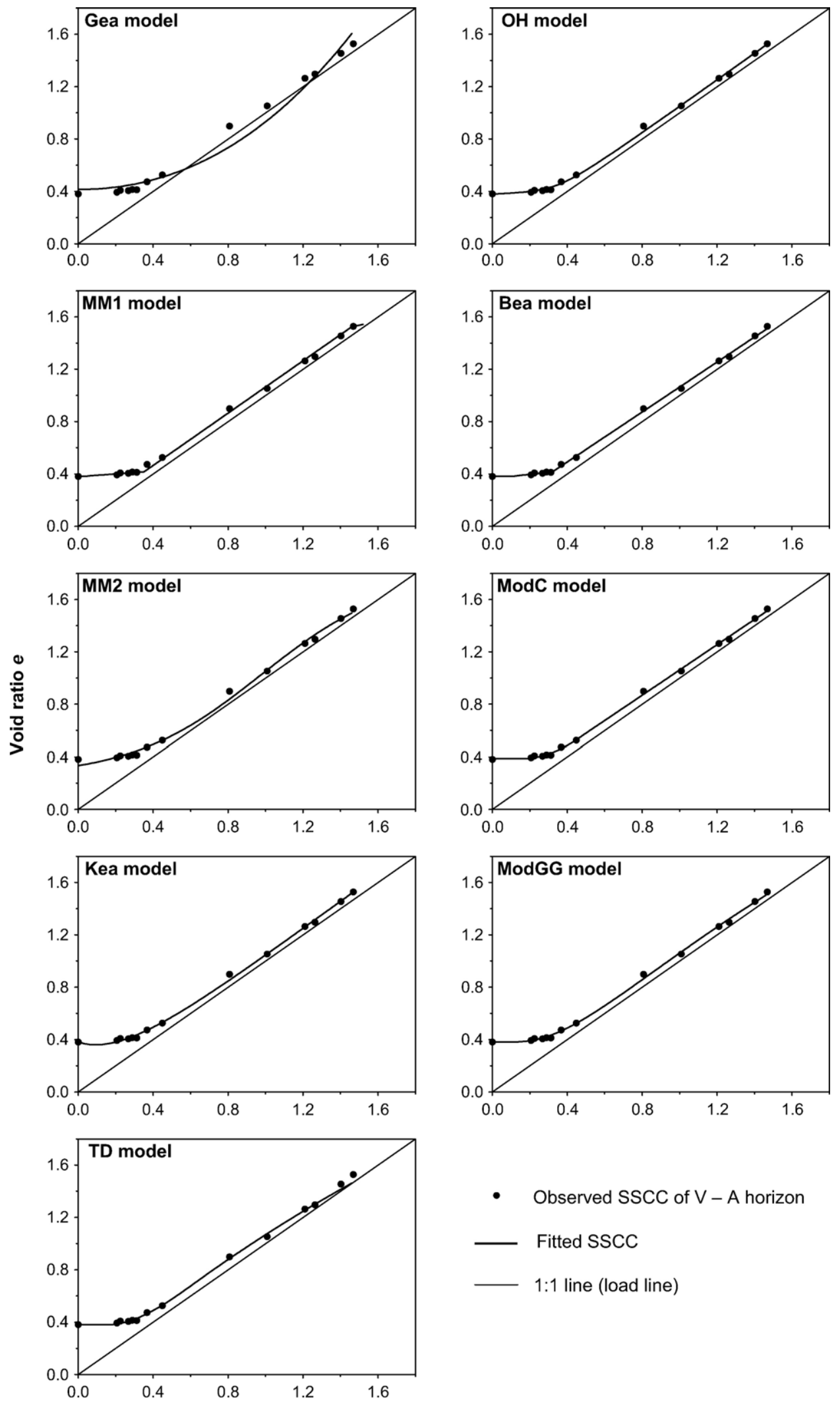

- Observed SSCC of V - A horizon

\section{Fitted SSCC}

1:1 line (load line)

Moisture ratio $\vartheta$

Fig. 7. Observed soil shrinkage characteristic curve of the A horizon of the Vertisol and soil shrinkage characteristic curves fitted using the models of Giráldez et al. (1983; Gea), McGarry and Malafant (1987; MM1, MM2), Kim et al. (1992; Kea), Tariq and Durnford (1993b; TD), Olsen and Haugen (1998; OH), Braudeau et al. (1999; Bea), and the modified models of Chertkov (2000, 2003; ModC) and Groenevelt and Grant (2001, 2002; ModGG). 

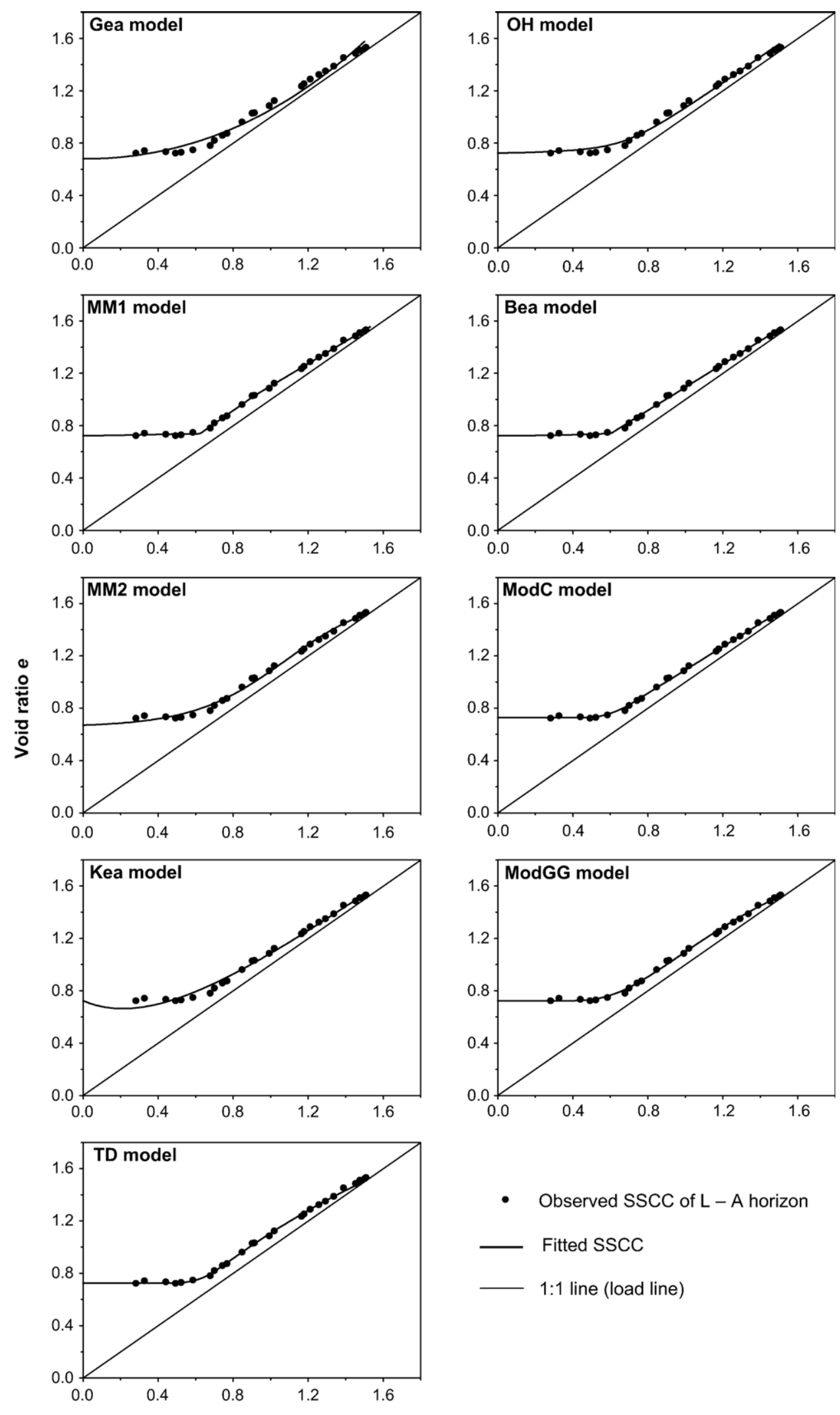

- Observed SSCC of L - A horizon

Fitted SSCC

1:1 line (load line)

\section{Moisture ratio $\vartheta$}

Fig. 8. Same as Fig. 7, but for the A horizon of the Lixisol. 
performance of Gea was also reported by McGarry and Malafant (1987).

With respect to the mean of AIC, similar groups can be observed. For the group of best performing models (cfr. letters ' $a$ ' and ' $a b$ ' in this case), Bea had the highest, i.e. least negative, AIC value. This was due to its relative large number of model parameters as a result of the theoretical considerations, including continuity at the end points of the different shrinkage zones. It should further be mentioned that the division of the structural zone in two zones in Bea and hence the introduction of additional model parameters, was not advantageous for our soils which showed no or limited structural shrinkage. Nevertheless, the relatively large number of parameters in the Bea model could result in large variances of the estimated model parameters for similar soils, and in a high degree of correlation between the parameters if the number of observations is limited. However, the mean AIC value computed for Bea was not significantly different from those of all the other models, except Gea. The lowest AIC can be observed for ModC. The latter has, however, a more complex structure than the ModGG model and required more computational time in determining its parameter values. Also the original Groenevelt and Grant $(2001,2002)$ model needed more computational time than ModGG (Cornelis et al., 2006).

To illustrate the behaviour of the nine models, observed and fitted SSCCs are compared in Fig. 7 for the A horizon of the Vertisol and in Fig. 8 for the A horizon of the Lixisol. It is clear that in particular the models which showed the highest performance, i.e. Bea, MM1, ModC and ModGG, followed the data very well. They further have sufficient flexibility, except for MM1, which does not describe the zero shrinkage zone. This means that the model in its current notation is not suitable to express the complete SSCC. Also the less performing MM2 and Kea have no distinct zero shrinkage zone. Kea even showed an increase in void ratio with decreasing moisture ratio after having reached a minimum void ratio value (see Fig. 8). Lower flexibility was also observed for TD and OH (see Figs. 7 and 8 respectively). Gea finally showed the smallest flexibility and crosses the load line which is theoretically not possible.

\section{Summary and conclusions}

This study showed significant differences in the SSCC measured on undisturbed samples using the core method (Berndt and Coughlan, 1976) on one hand and on disturbed samples using the balloon method (Tariq and Durnford, 1993a) and soil clods using the paraffin-coated method (Lauritzen and Stewart, 1941) on the other hand. All samples and clods were taken from seven horizons of a Vertisol and a Lixisol which were under sugar cane in the Havana province, Cuba. The paraffin-coated method was selected as a reference as it represents relatively well the shrinkage behaviour of a soil matrix rather than the bulk soil with cracks.

The shrinkage behaviour of the soils tested in our study was less pronounced when applying the core method compared to both the balloon and paraffin-coated method that showed similar results. This was explained by the anisotropic shrinkage which was supported by the variation of the geometry factor with the moisture ratio. Also the reorientation of particles associated with the collection of undisturbed soil cores could have played a role. The most probable explanation is, however, the formation of small millimetric cracks in the undisturbed samples upon drying. The core method further showed much higher scatter compared to the balloon method. This was attributed to higher measuring errors and crumbling of small aggregates upon drying for the core method. The above observations, and the fact that the balloon method is easy in use and non-labour intensive, and that it provides well reproducible data using one single sample only, indicate that it is a good alternative for the paraffin-coated method if one wants to describe the SSCC at the scale of the soil matrix without cracks.

As for the models describing the SSCC, it was shown that the multi-equation models presented by McGarry and Malafant (1987), Braudeau et al. (1999) and Chertkov $(2000,2003)$ - the latter being modified in this study - and the sigmoid model of Groenevelt and Grant $(2001,2002)$ which was rewritten by Cornelis et al. (2006), were superior in terms of RMSE, $R^{2}$ and AIC compared to the other models tested in this study. However, the McGarry and Malafant (1987) model does not describe the zero shrinkage zone of the SSCC, whereas the Braudeau et al. (1999) model has a rather high number of parameters the latter contains seven parameters while the model of McGarry and Malafant (1987), the modified Chertkov model $(2000,2003)$ and the modified Groenevelt and Grant model (Cornelis et al., 2006) contain respectively five, four and four parameters. Overall best performance was observed for the Chertkov $(2000,2003)$ model which was modified in this study to enable its use for soils in general, rather than for clay pastes only as in its original version. However, the modified Groenevelt and Grant model (Cornelis et al., 2006) has the advantage of being the most elegant and simple in structure it only needs one single equation to describe the complete SSCC - and hence requires less computational time in determining its parameter values. The simple structure is also advantageous when incorporating a SSCC into a model for computing water and solute transport.

\section{Acknowledgements}

The research work was conducted in the framework of the project "Improving soil salinity management under sugar cane using Geoinformatica" which was funded by the Flemish Interuniversity Council, Belgium, to which we are greatly indebted. The helpful comments and suggestions of Ary Bruand and an anonymous reviewer are also greatly acknowledged.

\section{References}

Akaike, H., 1974. New look at the statistical-model identification. IEEE Trans. Automat. Contr. AC19, 667-673.

ASTM, 2005. Test method for shrinkage factors of soils by the mercury method D427-04. Book of standards volume: 04.08. Committee D18.03 on Texture, Plasticity and Density Characteristics of Soils. 4 pp.

Berndt, R.D., Coughlan, K.J., 1976. The nature of changes in bulk density with water content in a cracking clay. Aust. J. Soil Res. 15, 27-37. 
Brasher, B.R., Franzmeier, D.P., Valassis, V., Davidson, S.E., 1966. Use of saran resin to coat natural soil clods for bulk density and water retention measurements. Soil Sci. 101, 108.

Braudeau, E., 1987. Mesure automatique de la rétraction d'échantillons de sol non remaniés. Science du Sol 25, 85-93.

Braudeau, E., Boivin, P., 1995. Transient determination of shrinkage curve for undisturbed soil samples: a standardized experimental method. In: Baveye, P., McBride, M.B. (Eds.), Clay Swelling and Expansive Soils. Kluwer Academic, Norwell, MA.

Braudeau, E., Costantini, J.M., Bellier, G., Colleuille, H., 1999. New device and method for soil shrinkage curve measurement and characterization. Soil Sci. Soc. Am. J. 63, 525-535.

Bronswijk, J.J.B., 1990. Shrinkage geometry of a heavy clay soil at various stresses. Soil Sci. Soc. Am. J. 54, 1500-1502.

Bronswijk, J.J.B., 1991. Relation between vertical soil movements and watercontent changes in cracking clays. Soil Sci. Soc. Am. J. 55, 1220-1226.

Bruand, A., Prost, R., 1987. Effect of water content on the fabric of a soil material: an experimental approach. J. Soil Sci. 38, 461-472.

Cabidoche, Y.-M., Voltz, M., 1995. Non-uniform volume and water content changes in swelling clay soil: II. A field study on a Vertisol. Eur. J. Soil Sci. $46,345-355$.

Chertkov, V.Y., 2000. Modeling the pore structure and shrinkage curve of soil clay matrix. Geoderma 95, 215-246.

Chertkov, V.Y., 2003. Modelling the shrinkage curve of soil clay pastes. Geoderma 112, 71-95.

Chertkov, V.Y., 2005. The shrinkage geometry factor of a soil layer. Soil Sci. Soc. Am. J. 69, 1671-1683.

Chertkov, V.Y., Ravina, I., 1998. Modeling the crack network of swelling clay soils. Soil Sci. Soc. Am. J. 62, 1162-1171.

Chertkov, V.Y., Ravina, I., Zadoenko, V., 2004. An approach for estimating the shrinkage geometry factor at a moisture content. Soil Sci. Soc. Am. J. 68, $1807-1817$

Corluy, J., 2001. Studie van de waterbalans in verzilte bodems van een suikerrietplantage in Cuba. M.Sc. thesis, Ghent University.

Cornelis, W.M., Corluy, J., Medina, H., Hartmann, R., Van Meirvenne, M., Ruiz, M.E., 2006. A simplified parametric model to describe the magnitude and geometry of soil shrinkage. Eur. J. Soil Sci. 57, 258-268.

Crescimanno, G., Provenzano, G., 1999. Soil shrinkage characteristic curve in clay soils: measurement and prediction. Soil Sci. Soc. Am. J. 63, 25-32.

Giráldez, J.V., Sposito, G., 1983. A general soil volume change equation: II. Effect of load pressure. Soil Sci. Soc. Am. J. 47, 422-425.

Giráldez, J.V., Sposito, G., Delgado, C., 1983. A general soil volume change equation: I. The two-parameter model. Soil Sci. Soc. Am. J. 47, 419-422.

Groenevelt, P.H., Bolt, G.H., 1972. Water retention in soil. Soil Sci. 113, 238-245.

Groenevelt, P.H., Grant, C.D., 2001. Re-evaluation of the structural properties of some British swelling soils. Eur. J. Soil Sci. 52, 469-477.

Groenevelt, P.H., Grant, C.D., 2002. Curvature of shrinkage lines in relation to the consistency and structure of a Norwegian clay soil. Geoderma 106, 235-245.

Grossman, R.B., Brasher, B.R., Franzmeier, D.P., Walker, J.L., 1968. Linear extensibility as calculated from natural-clod bulk density measurements. Soil Sci. Soc. Am. Proc. 32, 570-573.

Haines, W.B., 1923. The volume changes associated with variations of water content in soil. J. Agric. Sci. Cambridge 13, 293-310.

Hoogmoed, W.B., Bouma, J., 1980. A simulation-model for predicting infiltration into cracked clay soil. Soil Sci. Soc. Am. J. 44, 458-461.

Johnston, J.R., Hill, H.O., 1944. A case study of the shrinkage and swelling properties of Redzina soils. Soil Sci. Soc. Am. Proc. 24-29.

Jury, W.A., Gardner, W.R., Gardner, W.H., 1991. Soil Physics, 5th edition. John Wiley and Sons, New York, NY.

Kim, D.J., Vereecken, H., Feyen, J., Boels, D., Bronswijk, J.J.B., 1992. On the characterization of properties of an unripe marine clay soil. 1. Shrinkage processes of an unripe marine clay soil in relation to physical ripening. Soil Sci. $153,471-481$.

Lauritzen, C.W., 1948. Apparent specific volume and shrinkage characteristics of soil materials. Soil Sci. 65, 155-179.

Lauritzen, C.W., Stewart, A.J., 1941. Soil-volume changes and accompanying moisture and pore-space relationships. Soil Sci. Soc. Am. Proc. 6, $113-116$.

McGarry, D., Malafant, K.W.J., 1987. The analysis of volume change in unconfined units of soil. Soil Sci. Soc. Am. J. 51, 290-297.

McIntyre, D.S., Stirk, G.B., 1954. A method for determination of apparent density of soil aggregates. Aust. J. Agric. Res. 5, 291-296.

Michel, J.-C., Beaumont, A., Tessier, D., 2000. A laboratory method for measuring the isotropic character of soil swelling. Eur. J. Soil Sci. 51, 689-697.

Mitchell, A.R., 1992. Shrinkage terminology: escape from "normalcy". Soil Sci. Soc. Am. J. 56, 993-994.

Monnier, G., Stengel, P., Fiès, J.-C., 1973. Une méthode de mesure la densité apparente de petits agglomérats terreux. Application à l'analyse de systèmes de porosité du sol. Ann. Agron. 24, 533-545.

Nelder, J.A., 1961. The fitting of a generalization of the logistic curve. Biometrics 17, 89-110.

Nelder, J.A., 1962. An alternative form of a generalized logistic equation. Biometrics 18, 614-616.

Newman, A.C.D., Thomasson, A.J., 1979. Rothamsted studies on soil structure. III. Pore size distributions and shrinkage processes. J. Soil Sci. 30, 415-439.

Olsen, P.A., Haugen, L.E., 1998. New model of the shrinkage characteristic applied to some Norwegian soils. Geoderma 83, 67-81.

Pellissier, J.P., 1991. The toluene and wax-freezing method of determining volumetric free swell. Geotech. Test. J. 14, 309-314.

Philip, J.R., 1969. Hydrostatics and hydrodynamics in swelling soils. Water Resour. Res. 5, 1070-1077.

Press, W.H., Teukolsky, S.A., Vetterling, W.T., Flannery, B.P., 1992. Numerical Recipes in C. Cambridge University Press, Cambridge.

Rijniersce, K., 1983. A Simulation Model for Physical Soil Ripening in the IJsselmeerpolders. Rijksdienst voor de IJsselmeerpolders, Lelystad.

Schafer, W.M., Singer, M.J., 1976. A new method of measuring shrink-swell potential using soil pastes. Soil Sci. Soc. Am. J. 40, 805-806.

Sibley, J.W., Williams, D.J., 1989. A procedure for determining volumetric shrinkage of an unsaturated soil. Geotech. Test. J. 12, 181-187.

Soil Conservation Service, 1972. Guide for Interpreting Engineering Uses of Soils. U.S. Department of Agriculture, U.S. Government Printing Office, Washington DC.

Sposito, G., 1973. Volume changes in swelling clays. Soil Sci. 115, 315-320.

Sposito, G., Giráldez, J.V., 1976. Thermodynamic stability and law of corresponding states in swelling soils. Soil Sci. Soc. Am. J. 40, 352-358.

Stirk, G.B., 1954. Some aspects of soil shrinkage and the effect of cracking upon water entry into the soil. Aust. J. Agric. Res. 5, 279-290.

Tariq, A., Durnford, D.S., 1993a. Soil volumetric shrinkage measurements: a simple method. Soil Sci. 155, 325-330.

Tariq, A., Durnford, D.S., 1993b. Analytical volume change model for swelling clay soils. Soil Sci. Soc. Am. J. 57, 1183-1187.

van Dam, J.C., Huygen, J., Wesseling, J.G., Feddes, R.A., Kabat, P., van Walsum, P.E.V., Groenendijk, P., van Diepen, C.A., 1997. Theory of SWAP version 2.0. Simulation of Water Flow, Solute Transport and Plant Growth in the Soil-Water-Plant-Atmosphere Environment. Techn. Doc., vol. 45. Staring Centre, Agricultural Research Dept., Wageningen, The Netherlands. WRB, 1998. World Reference Base for Soil Resources. FAO, Rome.

Yule, D.F., Ritchie, J.T., 1980a. Soil shrinkage relationships of Texas Vertisols. 1. Small cores. Soil Sci. Soc. Am. J. 44, 1285-1291.

Yule, D.F., Ritchie, J.T., 1980b. Soil shrinkage relationships of Texas Vertisols. 2. Large cores. Soil Sci. Soc. Am. J. 44, 1291-1295. 